\title{
An intelligent irrigation system based on internet of things (IoT) to minimize water loss
}

\author{
Samar Amassmir, Said Tkatek, Otman Abdoun, Jaafar Abouchabaka \\ Computer Sciences Research Laboratory, Faculty of Sciences, Ibn Tofail University, Kenitra, Morocco
}

\begin{tabular}{|c|c|}
\hline Article Info & ABSTRACT \\
\hline Article history: & \multirow{10}{*}{$\begin{array}{l}\text { This paper proposes a comparison of three machine learning algorithms for a } \\
\text { better intelligent irrigation system based on internet of things (IoT) for } \\
\text { differents products. This work's major contribution is to specify the most } \\
\text { accurate algorithm among the three machine learning algorithms (k-nearest } \\
\text { neighbors (KNN), support vector machine (SVM), artificial neural network } \\
\text { (ANN)). This is achieved by collecting irrigation data of a specific products } \\
\text { and split it into training data and test data then compare the accuracy of the } \\
\text { three algorithms. To evaluate the performance of our algorithm we built a } \\
\text { system of IoT devices. The temperature and humidity sensors are installed in } \\
\text { the field interact with the Arduino microcontroller. The Arduino is } \\
\text { connected to Raspberry Pi3, which holds the machine learning algorithm. It } \\
\text { turned out to be ANN algorithm is the most accurate for such system of } \\
\text { irrigation. The ANN algorithm is the best choice for an intelligent system to } \\
\text { minimize water loss for some products. }\end{array}$} \\
\hline Received Jun 11, 2021 & \\
\hline Revised Oct 29, 2021 & \\
\hline Accepted Nov 23, 2021 & \\
\hline Keywords: & \\
\hline Arduino & \\
\hline Intelligent & \\
\hline IoT & \\
\hline Irrigation & \\
\hline Raspberry Pi3 & \\
\hline
\end{tabular}

This is an open access article under the CC BY-SA license.

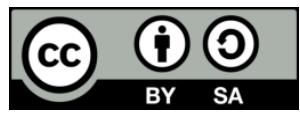

\section{Corresponding Author:}

Said Tkatek

Computer Sciences Research Laboratory, Faculty of Sciences, Ibn Tofail University

1400, Kenitra, Morocco

Email: said.tkatek@uit.ac.ma

\section{INTRODUCTION}

Morocco's agricultural sector is one of the most vulnerable. It is the primary source of income in some cities. Agriculture is becoming more productive today as a result of advances and new technologies such as sensors, devices, and information technology, which help generate a large amount of data [1]. Network parameter optimization (NPO) algorithm is a new metaheuristic optimization algorithm to simulate the human behavior in their motion when searching for water and food [2]. Perennials include olive, almond, pistachio, and fodder trees. The existing irrigation system is based on uniform water distribution [3] which is inefficient. As a result, agricultural monitoring technologies are being utilised. So, for the protection of farmers, to get the required production, we consider using artificial intelligence (AI), which plays an important role in developing good development and management practices, because agriculture will benefit tremendously from an intelligent approach powered by artificial intelligence. As a result, machine learning [4], a subset of artificial intelligence, plays a critical role in allowing machines to learn without being explicitly programmed. In farm management and production, numerous successful machine algorithms [5]-[7] recognise the input and correspondingly output the connection in agricultural inputs, producing an estimated forecast.

With the advent and growth of machine learning and internet of things (IoT), irrigation techniques are also becoming very modernized. The data retrieved by the sensors and the type of action done by the processor may be watched and modified by the user based on his needs, making the machine process more flexible based on real-time data [8] IoT, AI, and cloud computing [9]. When a precision irrigation system is 
used, the traditional system may be enhanced and the cost of farm management can be lowered. As a result, the farmer can decide on irrigation water by estimating the water need [10], [11]. The soil moisture status may be monitored using a soil moisture sensor to identify the present soil water content and irrigation depending on the moisture deficiency [12]. There are various methods for developing automated or smart irrigation systems that use sensors and are supported by IoT to allow for communication [13]-[22].

To perform a job in machine learning, the learning process is categorized into two categories. There are two types of learning: supervised learning and unsupervised learning. The irrigation system makes advantage of both of the learning processes. However, the most often used learning technique is supervised learning, which employs labelled data as an input data for training purposes. It is made up of both input components and the necessary result. The goal of using machine learning is to reduce the waste of water, so that when receiving informations from the sensors, the machine is able to make the right decision to allow irrigation or not. However, the major disadvantage of most of these systems is that they are completely reliant on the machine learning algorithm, which may be correct to some extent but cannot be accurate. Furthermore, irrigation is a land and crop specific process, so complete automation may result in unwanted extra water loss at times and excessive energy consumption from the system. The proposed work aims at comparison of three machine learning algorithms for a better intelligent irrigation system based on IoT for differents products which: i) Collecting irrigation data from web for training the machine learning algorithms while waiting for the collection of data of our next experiments which will be realized in the field of Gharb region (Morocco); ii) Specify which of the three algorithms (k-nearest neighbors (KNN), support vector machine (SVM), artificial neural network (ANN)) is more accurate; and iii) Uses IoT in field to evaluate the algorithm.

\section{METHOD}

In this paper, our objectif is to define an accurate algorithm among the three popular machine learning algorithms KNN, SVM, and ANN for an accurate intelligent irrigation system for a specific product. The steps we followed are: i) The very first step is to obtain the data that we need from available data sources and scrubbing it, "clean" and "filter" the data; ii) Split the data into training and test data then we made a model for each of the three algorithms (KNN, SVM, ANN), then calculate the accuracy for each one; and iii) we built a system of IoT devices, the temperature and humidity sensors are installed in the field interact with the Arduino microcontroller, the Arduino is connected to Raspberry Pi3 that holds the machine learning algorithm we found most accurate.

\subsection{Collecting and cleaning data}

Data collection is a crucial step; without data, we cannot proceed; thus, we must first decide where to collect data, whether it is from existing files or from the internet, using a web scraping tool that easily extracts massive quantities of data from the web. In our case, we will be collecting data from the web and the original owner of the database: Computer Application Department National Institute of Technology, Raipur. After collecting data, the most important step is cleaning data.

In the Table 1 sets of databases, we collected. As it turns out, we focused only on three types Wheat, Maize, and Potato. For each type, the data was checked and cleaned, so we obtained the number of data shown in the Table 1. In Figure 1 after collecting and cleaning the data. It was entered into the work environment where we used Google Colab. Colab is a free Jupyter notebook environment that runs entirely in the cloud. Colab supports many popular machine learning libraries. The Table 2 shows the details of the data collected.

Table 1. The number of data for each product

\begin{tabular}{cc}
\hline Product & The number of data \\
\hline Wheat & 100 \\
Maize & 125 \\
Potato & 100 \\
\hline
\end{tabular}

Table 2. Detailed data

\begin{tabular}{lcl}
\hline \multicolumn{1}{c}{ Name } & Unit of measure & \multicolumn{1}{c}{ Description } \\
\hline CropType & & Fixed numerical values \\
CropDays & & Days after sowing \\
SoilMoisture & DHT11 & Soil moisture, read by the soil moisture sensor \\
temperature & ${ }^{\circ} \mathrm{C}$ & Read by the temperature sensor \\
Humidity & $\%$ & Read by the humidity sensor \\
Pump (class) & & 1 for irrigated 0 for non-irrigated \\
\hline
\end{tabular}




\begin{tabular}{|c|c|c|c|c|c|c|c|}
\hline ( & print (Dat & taset) & & & & & \\
\hline \multirow[t]{12}{*}{ C } & Croptype & CropName & CropDays & SoilMoisture & Temperature & Humidity & pump \\
\hline & 1 & Wheat & 10 & 401 & 31 & 16 & $\theta$ \\
\hline & 1 & Wheat & 7 & 201 & 31 & 33 & $\theta$ \\
\hline & 1 & Wheat & 9 & 301 & 22 & 29 & $\theta$ \\
\hline & 1 & Wheat & 3 & 501 & 41 & 22 & $\theta$ \\
\hline & 1 & Wheat & 2 & 701 & 24 & 34 & $\theta$ \\
\hline & $\cdots$ & $\cdots$ & $\cdots$ & $\cdots$ & $\cdots$ & $\cdots$ & $\cdots$ \\
\hline & 3 & Potato & 106 & 668 & 18 & 67 & 1 \\
\hline & 3 & Potato & 108 & 189 & 21 & 65 & $\theta$ \\
\hline & 3 & Potato & 110 & 310 & 28 & 64 & $\theta$ \\
\hline & 3 & Potato & 112 & 467 & 19 & 63 & $\theta$ \\
\hline & 3 & Potato & 115 & 678 & 19 & 62 & 1 \\
\hline
\end{tabular}

Figure 1. The data printed in Colab

\subsection{Building model}

Generally, we will split our data, for the three algorithms, in two parts: training and testing sets. We train our model with training data, once it is ready to use, test it on test data to calculate the accuracy of each algorithm. We will take a known set of input data and known responses to the data (output) and trains a model to generate reasonable predictions for the response to new data. The algorithms used in our study are KNN, SVM, and ANN.

\subsubsection{K-nearest neighbors (KNN) algorithm}

The KNN method calculates the distance between each training sample and each test sample in the dataset and then provides the k-examples that are the closest. It has a linear time complexity and is guaranteed to discover the precise k-nearest neighbors. However, the linear search method's computing complexity is proportional to the size of the training dataset for each test sample, and it is $O(n d)$, where $n$ is the number of dimensions in the training dataset and $d$ is the number of dimensions in the training dataset [23], [24]. Our first working method is based on theses steps as: i) load the data, ii) separate data into $80 \%$ training data and $20 \%$ test data, iii) model creation, iv) train the model, v) verification of the accuracy of the model; vi) Make the prediction of a recording; and vii) Make the prediction with the test data.

\subsubsection{Support vector machine (SVM) algorithm}

SVMs are a family of machine learning (ML) algorithms that have good intrinsic generalization ability and are relatively robust to noise in the training data. Given a training data set, SVMs make at each data point an error of at most ' $\mathrm{e}$ ', where ' $\mathrm{e}$ ' is a predefined small positive number. SVMs were initially intended for linear models but non-linear ones can be made by transforming input $\mathrm{X}$ through a non-linear mapping $\Phi(X)$ and then applying conventional linear SVMs over features $\Phi(X)$. According to the data, the performance of SVM is the same order, or even better, than a neural network (NN) [25].

Our second working method is based on theses steps as: i) load the data; ii) separate data into $80 \%$ training data and $20 \%$ test data; iii) model creation; iv) train the model and predict the test data; v) verification of the accuracy of the model; vi) make the prediction of a recording; and vii) make the prediction with the test data.

\subsubsection{Artificial neural network (ANN) algorithm}

The ANN began with a simpler application in many disciplines and amazing success in pattern recognition (PR), especially in the manufacturing industry. Deep learning is one of the main machine learning technologies. A quite promising technique extends classical ANN by adding more complexity ("depth") to the model. Deep learning requires a large volume of data and the calculating power of machines to work well [26]. Despite the fact that great progress has been made and reviewed in resolving ANN application to PR concerns. ANN is among the most important algorithms that perform learning tasks. ANN are inspired by biological neural networks. Similarly, the ANN can learn from complicated data and provide insights through predictions or classifications [27]. To use this AI algorithm in data analysis, we will have to follow this working method.

Our third working method is based on theses steps as: i) load data; ii) separate data into $80 \%$ training data and $20 \%$ test data; iii) model creation (An entry layer with 10 nodes; A hidden layer having 20 nodes, An output layer having a node to predict); iv) compile the model; v) adapt and train the model by optimizing weights and biases; vi) evaluate the model; and vii) make probability predictions with the model. 


\section{RESULTS AND DISCUSSION}

The primary objective of model comparison and selection is definitely better performance of the machine learning software/solution. The objective is to narrow down on the best algorithms that suit both the data and the business requirements. After the implementation of machine learning algorithms, we obtaind the results of accuracy. In this work we use three algorithms KNN, SVM, and ANN. However, ANN algorithm gives very high result accuracy and Table 3 shown the comparison of accuracy result of using 3 machine learning algorithms.

Table 3. Accuracy result and comparison of machine learning algorithms

\begin{tabular}{lc}
\hline \multicolumn{1}{c}{ Algorithms } & Accuracy \\
\hline K-Nearest Neighbors KNN & $91 \%$ \\
Support Vector Machine SVM & $87 \%$ \\
Artificial Neural Network ANN & $96.81 \%$ \\
\hline
\end{tabular}

In the Table 3 it is clear that ANN machine learning algorithm gives accuracy result better than other applied machine learning algorithms. So according to this result the sensed data is then transmitted serially via serial communication to the Raspberry Pi3 control unit, which is running the machine learning algorithm ANN. The Pi3 control units employ a machine learning algorithm to train a data set pertaining to moisture and temperature for various soil conditions. The projected performance is sent to Arduino as a control signal, which activates the pump to water the field as required. The system is tested in two fields, the potato field and the wheat field, and it produced accurate results as the water pump was only opened when the field needed irrigation. The Figure 2 represents the flow diagram of the overall system, the ANN algorithm running in the Raspberry pi will check for various conditions from the data received from the nodes.

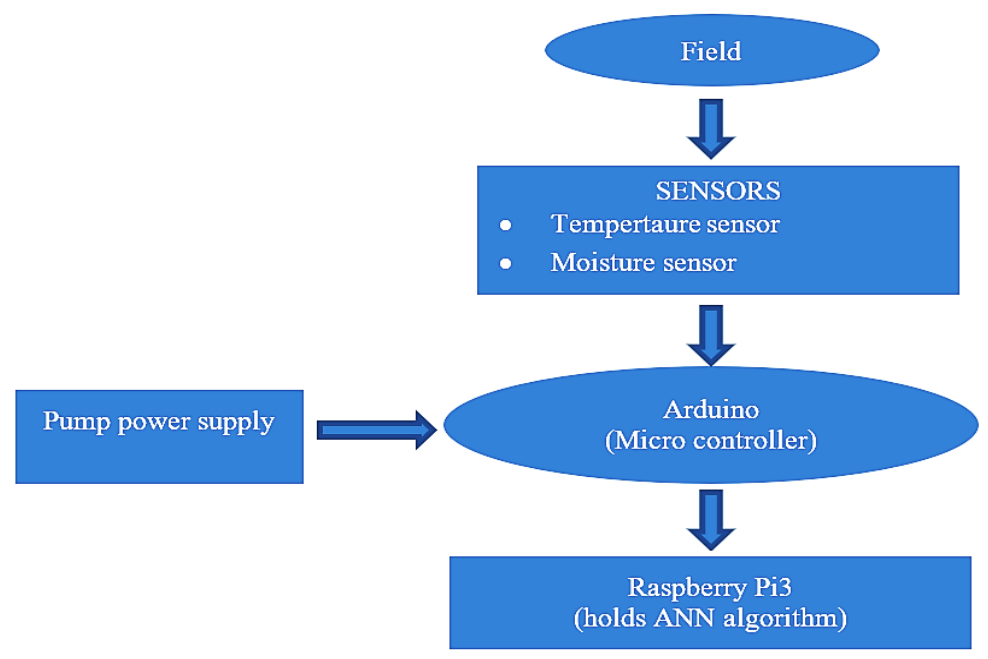

Figure 2. Intelligent irrigation system based on IoT

It took a lot of new technology to incorporate this application with an internet connection, such as sensors and Arduino, like viewpoints, on the one hand, it would be very important to implement this application that allows this device the ability to be controlled remotely. To improve our results we intend to integrate hybrid methods such as genetic algorithms [28]-[30]. We can use drones in agriculture wich their multifunction in areas with high risk of infection can ensure easy and safe distant interventions [31].

In the future, we can derive new ideas to develop our work such as smart urban farming service concept based on an open IoT platform [32], [33]. Using open source IoT platform such as (NodeMcu, Node Red, and message queue telemetry transport (MQTT)) [34]. As an automatic tool for monitoring the availability of water that can help the farmer to monitor the farm-field [35]. There is also a technologie a lowcost wireless sensor network (WSN) for detecting soil, environmental, and crop characteristics, which, when appropriately analyzed, are utilised in conjunction with weather forecasts to decide future agricultural operations based on agronomic models incorporated in the software platform [36]. To minimize water loss we can also build an application for automatic schedule-based distribution and monitoring of irrigation by 
applying the waterfall model process [37]. IoT with a fibrous capillary irrigation system based on the climatic demand estimated by the weather condition can also guarantee an accurate irrigation [38]. A modern intelligent gadget is created and used to manage the functioning of irrigation pumps across vast distances utilizing a strong way of communication to send information at the lowest cost and with the longest battery life.

\section{CONCLUSION}

Factors such as global climate change, food security development and consideration have prompted the company to pursue several innovative approaches to safeguard and improve crop yields. Agriculture may be a big business and thus the base of the economy. As a result, agriculture is changing over time as part of the company's technical growth. There is tremendous scope for the use of AI in agriculture and irrigation is among these uses, so AI can aid in decision-making on irrigation, applications of fertilizers and pesticides, detection of intrusions, detection of pests, predicting yield, prediction of plant diseases, and detection of fires

We provided a brief explanation of the importance of artificial intelligence in the field of agriculture in this article, then we chose irrigation as part of this sector. We worked to reduce the water consumption used for irrigation. We are responsible for ensuring automatic watering plants that enabled us to monitor the parameter of soil water quality and content in real time. In the future work, we will be interested in analyzing the data of the real experiences on the agricultural zone which knows a great irrigation activity and more specifically in Gharb region of Morocco.

\section{REFERENCES}

[1] A. H. Ali, R. F. Chisab, and M. J. Mnati, "A smart monitoring and controlling for agricultural pumps using LoRa IoT technology," Indonesian Journal of Electrical Engineering and Computer Science, vol. 13, no. 1, pp. 286-292, Jan. 2019, doi: 10.11591/ijeecs.v13.i1.pp286-292.

[2] S. Q. Salih and A. A. Alsewari, "A new algorithm for normal and large-scale optimization problems: Nomadic People Optimizer," Neural Computing and Applications, vol. 32, no. 14, pp. 10359-10386, Oct. 2020, doi: 10.1007/s00521-019-04575-1.

[3] Y. Kim, R. G. Evans, and W. M. Iversen, "Remote sensing and control of an irrigation system using a distributed wireless sensor network," IEEE Transactions on Instrumentation and Measurement, vol. 57, no. 7, pp. 1379-1387, Jul. 2008. doi: 10.1109/TIM.2008.917198

[4] K. Kaur, "Machine Learning: applications in indian agriculture," International Journal of Advanced Research in Computer and Communication Engineering, vol. 5, no. 4, pp. 342- 344, Apr. 2016, doi: 10.17148/IJARCCE.2016.5487.

[5] W. Okori and J. Obua, "Machine learning classification technique for famine prediction," Proceedings of the World Congress on Engineering, July 2011, pp. 2078-0966, doi: 978-988-19251-4-5.

[6] S. S. Dahikar and S. V. Rode," Agricultural crop yield prediction using artificial neural network approach," International Journal of Innovative Research in Electrical, Electronic, Instrumentation and Control Engineering, vol. 2, no. 1, pp. 2321-5526, Jan. 2014.

[7] R. Kumar, M. P. Singh, P. Kumar, and J. P. Singh, "Crop selection method to maximize crop yield rate using machine learning technique," Proceedings of International Conference on Smart Technologies and Management for Computing, Communication, Controls, Energy and Materials (ICSTM), Aug. 2015, vol. 5, no. 8, pp. 1751-1760, doi: 10.1109/ICSTM.2015.7225403.

[8] G. F. Savari, V. Krishnasamy, J. Sathik, Z. M. Ali, and S. H. E. A. Aleem "Internet of Things based real-time electric vehicle load forecasting and charging station recommendation," ISA Transactions, vol. 97, no. 7, pp. 431-447, Feb. 2020, doi: org/10.1016/j.isatra.2019.08.011.

[9] M. M. Subashini, S. Das, S. Heble, U. Raj, and R. Karthik, "Internet of things based wireless plant sensor for smart farming," Indonesian Journal of Electrical Engineering and Computer Science, vol. 10, no. 2, pp. 456-468, May 2018, doi: 10.11591/ijeecs.v10.i2.pp456-468.

[10] Z. Zhu, L. Tan, S. Gao, and Q. Jiao, "Observation on soil moisture of irrigation cropland by cosmic-ray probe," IEEE Geoscience and Remote Sensing Letters, vol. 12, no. 3, pp. 472-476, March 2015, doi: 10.1109/LGRS.2014.2346784.

[11] P. Hanswal, O. Dale, D. Gupta, and R. N. Yadav, "Designing a central control unit and soil moisture sensor based irrigation water pump system," Texas Instruments India Educ. Conf, Mar. 2013, vol. 5, no. 7, pp. 306-310, doi: 10.1109/TIIEC.2013.61.

[12] S. Navulur, A. S. C. S. Sastry, and M. N. G. Prasad, "Agricultural management through wireless sensors and internet of things," International Journal of Electrical and Computer Engineering (IJECE), vol. 7, no. 6, pp. 3492-3499, Dec. 2017, doi: 10.11591/ijece.v7i6.pp3492-3499.

[13] P. A. Patil, B. G. Jagyasi, J. Raval, N. Warke, and P. P. Vaidya, "Design and development of wearable sensor textile for precision agriculture," 7th International Conference on Communication Systems and Networks (COMSNETS), Jan. 2015, pp. 4799-8439, doi: 10.1109/COMSNETS.2015.7098714.

[14] L. M. Rodrigues, G. P. Dimuro, D. T. Franco, and J. C. Fachinello, "A system based on interval fuzzy approach to predict the appearance of pests in agriculture," Joint IFSA World Congress and NAFIPS Annual Meeting (IFSA/NAFIPS), Jun. 2013, vol. 14, no. 2, pp. 1262-1267, doi: 10.1109/IFSA-NAFIPS.2013.6608583.

[15] K. Kanda, T. Ishii, T. Kameoka, K. Saitoh, and R. Sugano, "Field monitoring system using Agri-Server," Proceedings of SICE Annual Conference (SICE), Sept. 2011, pp. 2069-2072.

[16] J. B. Sanger, H. Sukoco, and S. K. Saptomo, "Reliable data delivery mechanism on irrigation monitoring system," Int. Conf. on Advanced Computer Science and Information Systems (ICACSIS), Oct. 2014, pp. 53-56, doi: 10.1109/ICACSIS.2014.7065878.

[17] A. Adriansyah and A. W. Dani, "Design of Small Smart Home system based on Arduino," Elect. Power Elect. Communications Controls and Informatics Seminar (EECCIS), Aug. 2014, vol. 23, no. 4, pp. 121-125, doi: 10.1109/EECCIS.2014.7003731.

[18] S. R. R. D. Purusothaman, R. Ramesh, V. Vijayaraghavan, and K. K. Bajaj, "Design of Arduino-based communication agent for rural Indian microgrids," IEEE Innovative Smart Grid Technologies - Asia (ISGT Asia), vol. 26, no. 15, pp. 630-634, May 2014, doi: 10.1109/ISGT-Asia.2014.6873865. 
[19] J. M. Gomes, P. M. Ferreira, and A. E. Ruano, "Implementation of an intelligent sensor for measurement and prediction of solar radiation and atmospheric temperature," IEEE 7th International Symposium on Intelligent Signal Processing, Sept. 2011, vol. 50, no. 5, pp. 1-6, doi: 10.1109/WISP.2011.6051713.

[20] M. S. Perez and E. Carrera, "Time synchronization in Arduino-based wireless sensor networks," Latin America Transactions IEEE (Revista IEEE America Latina), vol. 13, no. 2, pp. 455-461, Feb. 2015, doi: 10.1109/TLA.2015.7055564.

[21] G. F. Savari and V. Krishnasamy, "A fully automated lawn mower using solar panel," Journal of Adv Research in Dynamical \& Control Systems, vol. 10, no. 7, pp. 977-983, Jun. 2018.

[22] V. C. Bojan, I. G. Raducu, F. Pop, M. Mocanu, and V. Cristea, "Cloud-based service for time series analysis and visualisation in Farm Management System," IEEE International Conference on Intelligent Computer Communication and Processing (ICCP), Nov. 2015, vol. 13, no. 2, pp. 425-432, doi: 10.1109/ICCP.2015.7312697.

[23] X. Wu, C. Zhang, and S. Zhang, "Database classification for multi-database mining," Information System Information Systems (INFORM SYST), vol. 30, no. 1, pp. 71-88, Mar. 2005, doi: 10.1016/j.is.2003.10.001.

[24] R. Dahmani, A. Belmouzkia, S. Tkatek, and A. A. Fora, "Automatic slums identification around normal and smart cities: using Machine-learning on VHR Satellite Imagery," International Journal of Advanced Trends in Computer Science and Engineering , vol. 9, no. 5, pp. 235-236, Sep. 2020, doi: 10.30534/ijatcse/2020/312952020.

[25] L. Rabhi, N. Falih, L. Afraites, and B. Bouikhalene, "Digital agriculture based on big data analytics: a focus on predictive irrigation for smart farming in Morocco," Indonesian Journal of Electrical Engineering and Computer Science, vol. 24, no. 1, pp. 581-589, 2020, doi: 10.11591/ijeecs.v24.i1.pp581-589.

[26] N. Zhu et al, "Deep learning for smart agriculture: Concepts, tools, applications, and opportunities," Int. J. Agric. Biol. Eng., vol. 11, no. 4, pp. 32-44, Dec. 2018, doi: 10.25165/j.ijabe.20181104.4475

[27] H. Balti, I. Chebbi, N. Mellouli, I. R. Farah, and M. Lamolle, "A big remote sensing data analysis using deep learning framework," International Conferences Big Data Analytics, Data Mining and Computational Intelligence, Dec. 2019, pp. 119126, doi: 10.33965/bigdaci2019_201907L015.

[28] S. Tkatek, S. Bahti, O. Abdoun, and J. Abouchabaka, "Artificial-intelligence-for-improving-the-optimization-of-nphardproblems-A-review," International Journal of Advanced Trends in Computer Science and Engineering, vol. 9, no. 5, pp. 74117420, Oct. 2020, doi: 10.30534/ijatcse/2020/73952020.

[29] S. Tkatek, O. Abdoun, J. Abouchabaka, and N. Rafalia, "An optimizing approach for multi constraints reassignment problem of human resources," International Journal of Electrical and Computer Engineering, vol. 6, no. 4, pp. 1907-1919, Aug. 2016, doi: 10.11591/ijece.v6i4.9438.

[30] S. Tkatek, A. Belmzoukia, S. Nafai, J. Abouchabaka, and Y. Ibnou-ratib, "Putting the world back to work: An expert system using big data and artificial intelligence in combating the spread of COVID-19 and similar contagious diseases," Work, vol. 67, no. 3, pp. 557-572, Apr. 2020, doi: 10.3233/WOR-203309.

[31] S. Tkatek, S. Bahti, O. Abdoun, and J. Abouchabaka, "Intelligent system for recruitment decision making using an alternative parallel-sequential genetic algorithm," Indonesian Journal of Electrical Engineering and Computer Science, vol. 22, no. 1, pp. 385-395, Apr. 2021, doi: 10.11591/ijeecs.v22.i1.pp385-395.

[32] A. S. Oh, "Smart urban farming service model with IoT based open platform," Indonesian Journal of Electrical Engineering and Computer Science, vol. 20, no. 1, pp. 320-328, Oct. 2020, doi: 10.11591/ijeecs.v20.i1.pp320-328.

[33] N. Zainal, N. Mohamood, M. F. Norman, and D. Sanmutham "Design and implementation of smart farming system for fig using connected-argonomics," International Journal of Electrical and Computer Engineering, vol. 9, no. 6, pp. 5653-5662, Dec. 2019, doi: 10.11591/ijece.v9i6.pp5653-5662.

[34] R. Lakshmanan, M. Djama, S. K. Selvaperumal, and R. Abdulla, "Automated smart hydroponics system using internet of things," International Journal of Electrical and Computer Engineering, vol. 10, no. 6, pp. 6389-6398, Jun. 2020, doi:10.11591/ijece.v10i6.pp6389-6398.

[35] G. I. Hapsari, G. A. Mutiara, L. Rohendi, and A. Mulia, "Wireless sensor network for monitoring irrigation using XBee pro S2C," Bulletin of Electrical Engineering and Informatics vol. 9 no. 4, pp. 1345-1356, Dec. 2020, doi: 10.11591/eei.v9i4.1994

[36] P. Visconti, N. I. Giannoccaro, R. de Fazio, S. Strazzella, and D. Cafagna, "IoT-oriented software platform applied to sensorsbased farming facility with smartphone farmer app," Bulletin of Electrical Engineering and Informatics, vol. 9, no. 3, pp. 10951105, Jun. 2020, doi: 10.11591/eei.v9i3.2177.

[37] A. N. Afif, F. Noviyanto, S. Sunardi, S. A. Akbar, and E. Aribowo, "Integrated application for automatic schedule-based distribution and monitoring of irrigation by applying the waterfall model process," Bulletin of Electrical Engineering and Informatics, vol. 9, no. 1, pp. 420-426, Sep. 2020, doi: 10.11591/eei v9i1.1368.

[38] M. K. I. Abd Rahman, M. S. Z. Abidin, M. S. A. Mahmud, S. Buyamin, M. H. I. Ishak, and A. A. Emmanuel, “Advancement of a smart fibrous capillary irrigation management system with an internet of things integration," Bulletin of Electrical Engineering and Informatics, vol.8, no. 4, pp.1402-1410, Dec. 2019, doi: 10.11591/eei.v8i4.1606.

\section{BIOGRAPHIES OF AUTHORS}

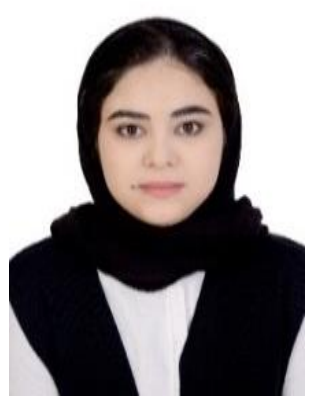

Samar Amassmir (D) $8 \mathrm{SC}$ S Her master's degree in computer science has been received from Ibn Zohr University. She is currently an Ibn Tofail University, Kenitro, Morocco, PhD student at the Computer Science Research Laboratory (LaRI). She can be contacted at email: samar.amasmir@gmail.com. 

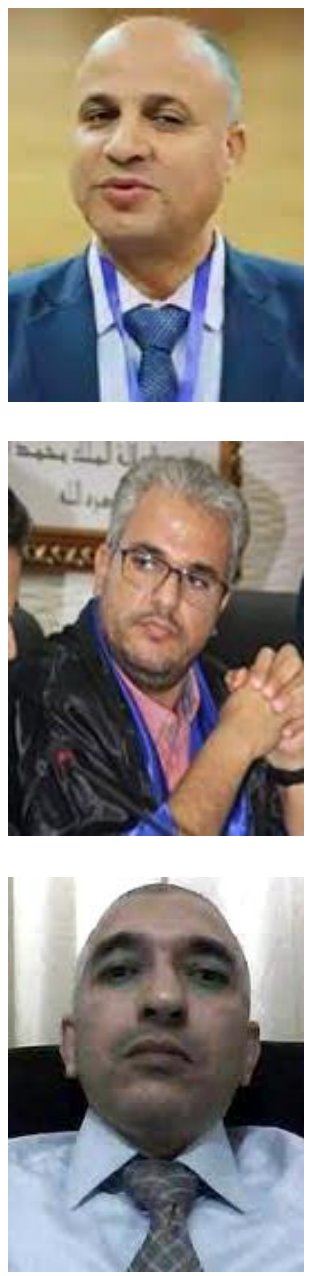

Said Tkatek (D) 8 SC P is Professor of Computing Science Research at the University of Kenitra, Faculty of Science, Ibn Tofail. Their study focuses on the optimisation of NP-Hard issues with the metaheuristic approaches in artificial intelligence and big data for decisionmaking in diverse fields. Includes big data analytics, artificial intelligence, information system, and human resources optimization. He can be contacted at email: said.tkatek@uit.ac.ma.

Otman Abdoun (iD 81 SC P Professor of Computer Science at Larache Abdelmalek University, Multidisciplinary Faculty. His work focuses on addressing the NP-Complete problem with methods of meta-heuristics to lessen the complexity of the problems investigated. He can be contacted at email: abdoun.otman@gmail.com.

Jaafar Abouchabaka (D) SC SC is a Professor of Computer Science at Ibn Tofail University in Kenitra, Faculty of Science. Their research is presently focused on the optimization and implementation of NP-hard Jaafar technology and big data analysis. Abouchabaka is the director of the research laboratory for computer sciences (La.R.I). He can be contacted at email: jaafar.abouchabaka@uit.ac.ma. 